\title{
UN ROMPEDOR INICIO DE SIGLO: SU IMPACTO SOBRE LA PUBLICIDAD, LOS MEDIOS DE COMUNICACIÓN Y EL CONSUMO
}

\section{A HOME BREAKER OF THE CENTURY: ITS IMPACT ON THE ADVERTISING, MEDIA AND CONSUMPTION}

\begin{abstract}
Elena Olabarri Fernández: Catedrática del Departamento de Comunicación Audiovisual y Publicidad. Universidad del País Vasco. mariaelena.olabarri@ehu.es
\end{abstract}

\section{RESUMEN}

La sociedad está en constante cambio. A este cambio debemos sumarle la velocidad, complejidad y profundidad de cambio socioeconómico que actualmente vivimos, y que necesariamente nos conduce a escenarios de incertidumbre y de riesgo. Anticipar qué nuevas pautas parecen desarrollarse resulta fundamental para identificar oportunidades y prever potenciales amenazas. El propósito de este artículo es presentar una reflexión sobre el impacto que en los medios de comunicación, la publicidad y en última instancia el consumo en su sentido más amplio, tienen estos nuevos escenarios.

\section{PALABRAS CLAVE}

Cambio - Publicidad - Medios de Comunicación - Consumo

\begin{abstract}
Society is undergoing a permanent change. Furthermore the speed, complexity and depth of the social and economic changes we are presently living through, lead us to a scenario of uncertainty and risk. In this context anticipating emerging working patterns becomes a basic starting point to identify opportunities and foresee potential threats. The aim of this article is to show a reflection on
\end{abstract}


the impact that such new scenarios have on the media, on advertising and last but not least, on consumption in its widest sense.

\title{
KEY WORDS
}

Change - Advertising - The media - Consumption

\section{ÍNDICE}

\author{
$\boldsymbol{\alpha}$ 1. INTRODUCCIÓN \\ $\boldsymbol{1}$ 2. ESTRATEGIAS ANTE LA INCERTIDUMBRE \\ 2.1. Involución, el regreso al pasado \\ 2.2. Recrear un mundo imaginario \\ 2.3. El cambio, por un nuevo modelo \\ 3. REFLEXIÓN FINAL
4. BIBLIOGRAFIA
}

\section{INTRODUCCIÓN}

La sociedad está en constante transformación, pero la velocidad, la complejidad y profundidad del cambio socioeconómico que actualmente vivimos, necesariamente nos conduce a escenarios de incertidumbre y de riesgo. De un mundo sólido con estructuras arraigadas hemos pasado inesperadamente a una situación de inseguridad, de fragilidad. La entrada al nuevo siglo supuso un clima de euforia que duró poco por el impacto de los sucesos que han acontecido, los atentados del 11 de septiembre y del 11 de marzo ,la guerra de Afganistán, la invasión de Irak, los shunamis, terremotos, las olas de calor, la supuesta pandemia de la gripe A, la amenaza fundamentalista y como no, la crisis económica. Todos estos acontecimientos han desestabilizado la relación con la actualidad y con el futuro. Nos encontramos en palabras de Bauman (2005) ante"la modernidad líquida" refiriéndose a un tiempo sin certezas, una sociedad líquida, cambiante. Ello ha provocado que la sensación de vulnerabilidad, de fragilidad, de inseguridad se dejen sentir entre nosotros. 
Las crisis ponen en cuestión nuestro saber sobre la realidad y la capacidad que tenemos de influir sobre ella. Poco a poco se desvanece una creencia que a lo largo de la historia se ha propuesto desde el mundo científico, político y económico y que ha animado al hombre como es, la asimilación de futuro igual a progreso. Podría pensarse que en el sentir general de los mortales está el aseverar que el avance de la historia es acumulativo, dirigido a aumentar la satisfacción. Sin embargo el nuevo milenio ha dejado gravemente dañada esta percepción, así como nuestra confianza en el futuro. El mundo de conocimiento, de seguridad, donde todo está más o menos predeterminado, ha llegado a su fin. La detención de un lugarteniente de Bin Laden, el juicio y posterior condena a muerte de Sadan Husseim, no han sido suficientes, las cosas han empeorado en Irak, por otro lado el éxito en la detención de los responsables del 11-M y el juicio de los mismos no mitiga los temores sobre las ramificaciones de la trama. En alguna medida ante las crisis se vuelve a tomar conciencia de la propia impotencia, de los límites en los que nos movemos pese a la promesa constante del futuro como bienestar y solución.

El sociólogo Robert Castel (2004) reflexiona sobre esta situación que denomina "inseguridad permanente" y que supone no poder controlar el presente ni anticipar positivamente el futuro. El autor plantea la hipótesis de que la inseguridad moderna no sería la ausencia de protecciones o medios sino todo lo contrario, una obsesiva manía vinculada a la búsqueda incesante de seguridad en un mundo social. Esa búsqueda frenética es la que genera el constante sentimiento de inseguridad. En otras palabras, estar protegido, sugiere el autor, significa estar amenazado. En palabras del autor:

"la imprevisibilidad de la mayor parte de nuevos riesgos, la gravedad y el carácter irreversible de sus consecuencias, hacen que la mejor prevención consista a menudo en anticipar lo peor y en tomar medidas para evitar que eso advenga, aun cuando sea muy aleatorio. Consiste en destruir, por ejemplo todo un rebaño de ganado ante la incertidumbre de que haya habido contaminación, 
al precio de consecuencias económicas y sociales desproporcionadas en relación con el riesgo real" (ibid: 78).

Para Castel, las sociedades modernas se encuentran viviendo una especie de "inflación del riesgo" en donde no existe una solución radical que haga desaparecer la ansiedad. Paradójicamente, a la vez que aumenta la demanda de protección decrece la posibilidad de sentirse protegido.

En consecuencia, anticipar qué nuevas pautas, qué estrategias y conductas parecen instalarse en nosotros ante la incertidumbre (característica de la sociedad actual) resulta fundamental para identificar oportunidades y prever potenciales amenazas. Por ello, el propósito de este artículo es presentar una reflexión sobre el impacto que la realidad actual tiene en los medios de comunicación, la publicidad y en última instancia, el consumo en su sentido más amplio. Nos encontramos, sin duda, en un momento propicio para el cambio de paradigmas y creencias (Rafa Garrido 2009). La publicidad y los medios de comunicación se enfrentan al desafío de comprender al consumidor para poder conectar con él.

La preocupación por conocer el impacto de estos cambios en el mundo del marketing ha sido estudiado desde diferentes perspectivas y puntos de vista. En el año 2005 la empresa Carat Expert realizó un estudio sobre el tema que se plasmó en una publicación sobre nuevas tendencias. Con posterioridad, desde Millward Brown (2009) y Synovate Censydian (2009) han abordado la misma cuestión. Todas ellas coinciden en mostrar cómo la conciencia de la incertidumbre ante esta crisis existencial y económica, se cristaliza en diversas respuestas, distintos comportamientos vitales.

La misión de este artículo será mostrar, a la reflexión del lector, distintas estrategias vitales del hombre, como respuesta a esta confusión consustancial con el desarrollo de la sociedad actual, así como su manifestación en la publicidad, los medios de comunicación y el consumo. Todo ello a partir de las aportaciones del estudio coordinado por Aitor Zuluaga desde Carat Expert, del cual este artículo pretende, en algún sentido, ser una actualización. 


\section{ESTRATEGIAS ANTE LA INCERTIDUMBRE}

Las respuestas del hombre ante la crisis pueden ser muy diversas. En este trabajo vamos a resumirlas en tres, extremas, antagónicas entre sí, donde cada una de ellas engloba otras muchas y que en conjunto recogen un abanico amplio de conductas. Tal y como se muestra el cuadro son las siguientes:

Estrategias vitales ante la incertidumbre

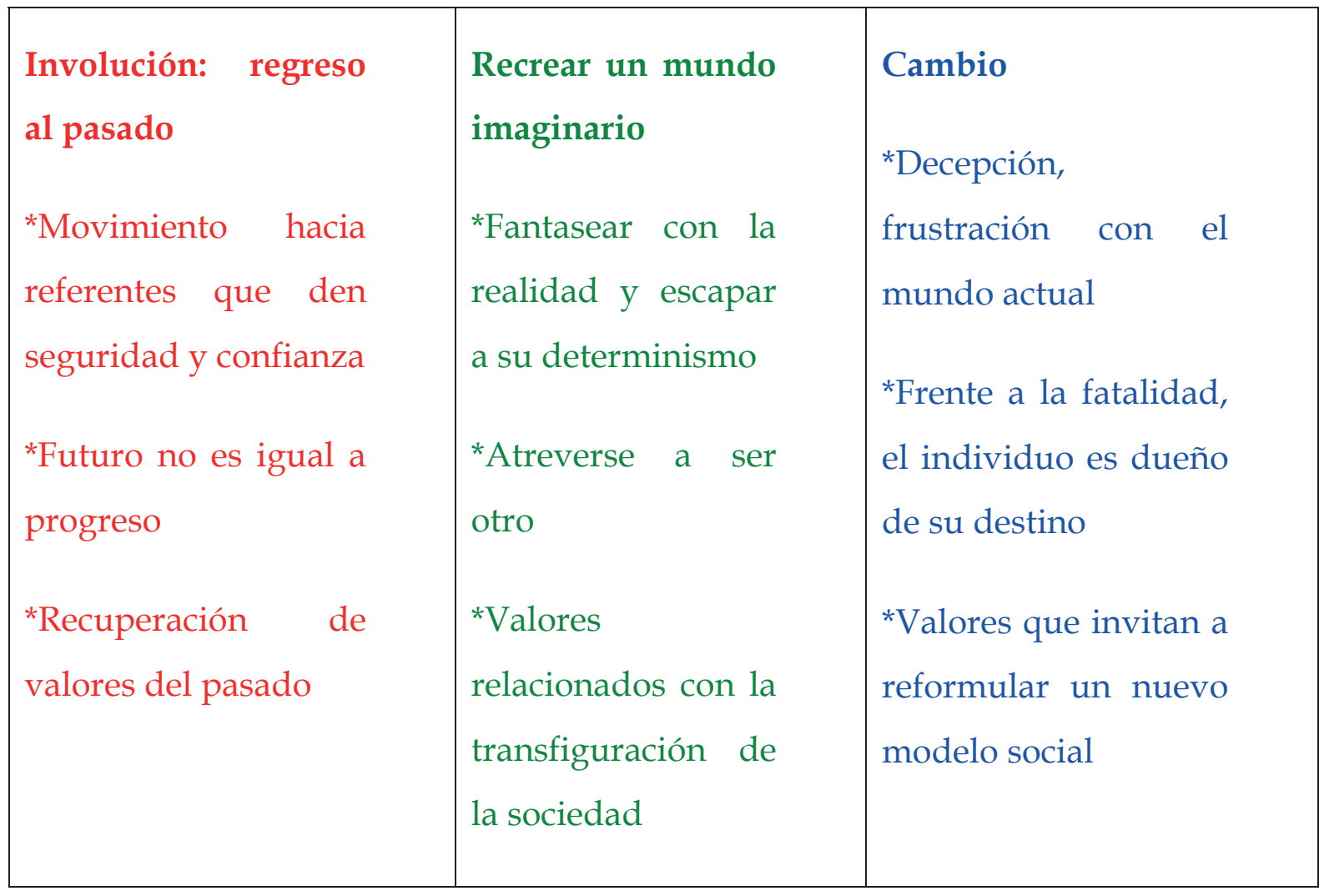

(Elaboración propia a partir del estudio de Carat Expert) 


\subsection{Involución, regreso al pasado}

Se trata de una estrategia defensiva y consiste en regresar al pasado. Significa, en su sentido más amplio, la búsqueda de protección, la necesidad de resguardarse en un mundo que nos garantice seguridad frente a las posibles amenazas del entorno.

Nos encontramos en un mundo de grandes cambios, de constante renovación, nuestros abuelos se asombraban con un cambio en su vida (la televisión, la penicilina...etc.), nosotros presenciamos cambios cada año, cada mes, incluso cada día. Ello no significa que podamos asumirlos en toda su extensión y es lógico que el ser humano sienta miedo a perder todo lo que con su trabajo y esfuerzo ha conseguido, por eso es muy frecuente la demanda de seguridad. ¿Dónde encontrar la seguridad, la tranquilidad?, probablemente en lo conocido. En este sentido, el recurso al pasado supone la búsqueda de unas coordenadas conocidas que nos ayuden a guiarnos, implica la certeza de estar bien orientados respecto al futuro.

La involución es una estrategia de repliegue que consiste, como apunta I. Zuluaga (2005), "en retirarse a una esfera vital bajo control. Es como si aspirásemos a vivir dentro de burbujas que nos protejan y nos mantengan seguros frente al mundo exterior". El objetivo último es proteger la identidad propia a cualquier precio. Se trata de un control de los detalles de la vida cotidiana.

Las consecuencias inmediatas de esta estrategia se plasman en distintos comportamientos. Así esta necesidad de control se traduce, por un lado, en un deseo de urgencia . Todo debe suceder en un abrir y cerrar de ojos, por ello la solución que se impone es la de mensajes fuertes, en una lógica de problema/solución. Nos resulta exasperante la lentitud. Nos interesa tanto poder hablar ingles como hablarlo en un período de 6 meses. Obtener resultados visibles con los cosméticos en semanas. Si deseamos adelgazar, queremos resultados en días ("Plan Special K en 15 días”). Esta especie de dictadura de lo instantáneo también es observable en los medios de 
comunicación. Podemos constatar, por ejemplo, en los informativos televisivos una obsesión por dar la apariencia de actualidad. Se sirven las noticias en crudo, sin pasarlas por el filtro de la certeza aún a riesgo de incurrir en errores.

Otra consecuencia es vivir con intensidad el deseo de retornar al pasado, de recuperar lo perdido con el fin de retrasar en lo posible la incertidumbre. Es la confirmación del adagio de que "cualquier tiempo pasado fue mejor". Todo lo que pueda retrotraernos a un pasado en el que nos sintamos más seguros resulta efectivo. En el ámbito del consumo muchas marcas apuestan por la tradición, de ahí que la creatividad publicitaria recoge estas nostalgias y nos presente mensajes que nos retrotraen a nuestra niñez. Son muchos los campos en los que podemos observar esta tendencia, a modo de ejemplo citaremos algunos:

En el terreno musical están de moda las recopilaciones en CD de los éxitos de los años 70, 80 y 90. La emisora musical Kiss F.M. consigue situarse en el grupo de las cadenas líderes en muy pocos años. En la literatura podemos constatar el éxito de libros que vuelven su mirada al medievo como "Los Pilares de la tierra", "La catedral del mar" o "Te doy la tierra". En el cine se recuperan éxitos de la televisión de los años 70 y 80 como "Los Ángeles de Charlie" o "Starsky y Hutch". También la vuelta a historias del pasado con recientes estrenos de películas como "Gladiador" o una nueva versión de "Robin Hood." En abril de 2010, se ha estrenado en la gran pantalla "El pequeño Nicolás", adaptando los cuentos que han marcado a más de una generación desde los años 50. Y en televisión, temporada tras temporada se emite la serie "Cuéntame como pasó". Incluso ha llegado a generar un nuevo programa en busca de cantantes que encarnen a los protagonistas, así como un musical de la misma. En Antena 3 se estrena la segunda temporada de "Curso del 63". También en la automoción podemos encontrar ejemplos, así vuelven a estar de moda, el coche Mini, el Fiat 500 o el Chrisler PT Cruiser. 
En este sentido Cortadillas y Malillos, A.(2010) apuntan como las marcas de productos de consumo están aplicando esta estrategia:

"un camino que actualmente están desarrollando muchas marcas es el "paternalismo". Estas marcas ofrecen estabilidad, acompañamiento, seguridad, protección, en un entorno que el consumidor siente como inestable, cambiante e inseguro. Los consumidores piden garantías. Este tipo de estrategia puede trabajarse a través de la historia y permanencia de las marcas, a través de una línea continuista que demuestre que más allá de las circunstancias, siempre hay elementos inalterables que protegen y dan seguridad, referentes que suponen un regreso a lo básico, a lo importante, a lo perenne".

A juicio de los autores, un gran número de marcas como Ariel, Pascual, Danone o Nestlé ya lo han desarrollado.

Sin embargo, en un mundo fundado en la conciencia de la incertidumbre, la necesidad de sentirse protegido no se satisface solamente con la búsqueda de las raíces, también se anima a buscar un nido abrigado donde el individuo pueda encerrarse en su caparazón y desconectar. Los anuncios de Tecnocasa: "Porque sabemos que en casa es como mejor se está" o de IKEA: “Bienvenido a la república independiente de tu casa”, aluden a esta especie de burbuja protectora.

En este sentido, el hogar es sin duda un entorno protector y esta protección comporta un incremento en el interés de todo lo relacionado con la decoración, revistas, tiendas de interiorismo...etc. Así, por ejemplo, Zara, el gigante de la confección inaugura una nueva línea de negocio "Zara Home". Junto a ello se detecta un incremento en las páginas dedicadas a la decoración e interiorismo en las ediciones de los suplementos dominicales, con ello, lo convencional, lo poco atractivo da paso a lo creativo. Se observa una gran preocupación por embellecer el entorno para luego fijarse en él. Las ciudades buscan hacer habitables las calles, los parques y los lugares peatonales. Hemos 
aumentado el consumo de plantas y elementos decorativos que priman el atractivo externo frente a lo práctico, frente a lo uniforme.

Uno puede mantenerse mucho tiempo sin salir de la burbuja gracias a las nuevas tecnologías que nos permiten trabajar a distancia o recibir múltiples servicios. La búsqueda de comodidad y seguridad lleva a considerar el hogar como principal centro de ocio y consumo. Se trata de una tendencia conocida como cooking y significa una mayor permanencia en el hogar y por tanto el creciente protagonismo de éste como ámbito de consumo y de actividad profesional. Las consecuencias de esta tendencia pueden darse en diversas vertientes. De un lado el aumento de servicios de actividades tales como entrega a domicilio, asistencia doméstica desde la plancha a cualquier actividad relacionada con el hogar. Por otro lado nuevos conceptos de vivienda en los que prima la automatización y la domótica, y por último el negocio de la seguridad.

Basta con pinchar en www.dedica.es para ponernos en contacto con una empresa de servicios integrales del hogar, desde limpieza, pasando por cocineros, camareras, cuidado de niños y ancianos, clases particulares a domicilio, etc. Quizá nos interesa un servicio a domicilio de bebidas, flores, pinchadiscos, o un completo catálogo de obsequios.

Vivir en un mundo de protección también puede significar la necesidad urgente de la atribución de responsabilidades. No nos bastan los hechos, necesitamos comprender por qué son como son y una parte de esa comprensión incluye la atribución de causalidad. Parece necesario asignar responsabilidades para sentirse seguro. Como constatan desde Carat (2005), la publicidad, el crédito al consumo, el tabaco, el coche...etc., día a día aumenta el número de campos de la vida cotidiana que se transforman en vías para la "estigmatización". Las marcas han de estar preparadas para que las pongan en el banquillo de los acusados, no sólo por los consumidores sino también por las propias instituciones. 
En una burbuja resguardada, el individuo, se basta sólo, se convierte en centro del sistema solar y con ello la egología es una consecuencia natural. Como expresa I. Zuluaga (2005):

"La egología es la ciencia de ocuparse de uno mismo, de ocupar el terreno, de reforzarse, de revaluarse y de figurar, por todos los medios posibles. Estamos ante un resurgir del narcisismo. El individuo se encuentra cada vez más en el centro del consumo. Todos los beneficios se relacionan con la satisfacción personal: sensaciones del café, placer de conducir....etc."

Todo ha de ser a la vez uno mismo y una prolongación de la persona: la casa, el coche, la ropa y el entorno son, en realidad, reflejos y espejos. Los niños, la pareja, la familia y amigos pueden, en principio, confirmar su identidad. Así el niño puede ser un doble, una extensión de uno mismo e incluso un accesorio. Llevarse el niño a todos los lados es una práctica común en Madonna, las Spice Girls o Angelina Jolie.

Este gusto por el "yo" ya lo intuyeron hace unos años los expertos en marketing. Así tras el marketing de masas, el marketing de la persona está en plena emergencia para dar al consumidor la ilusión halagadora de la compra por encargo, a medida. En palabras de Javier Rovira (2009) “el consumidor pasa por lo tanto de la diferenciación y del mass-customization al self-customization. El mensaje es sencillo "dejame que yo lo haga.......si quiero". Ello explica el éxito exponencial del objeto en serie limitada o del objeto único, desde los bolsos personalizables, hasta el tunning telefónico o del automóvil. Louis Vuitton lanza al mercado sus bolsos por encargo. Los clientes pueden elegir el tamaño, el material y el color e, incluso, bordar o grabar sus iniciales si lo desean.

Por último resulta insoportable no tener respuesta a las preguntas existenciales. Por ello ante el desencanto de la religión tradicional se acude a adaptaciones personalistas y a la búsqueda de otras que ofrezcan novedad: de ahí el incremento de las sectas, el interés por fenómenos paranormales, las filosofías orientales, las ciencias ocultas o el tarot. El individuo busca alternativas al "Dios de sus padres". De un clima de cristiandad se ha 
pasado a un ambiente más secularizado. Asistimos a un proceso de cambio donde se paganiza lo sagrado y se sacraliza lo pagano. Surgen academias especializadas, lugares donde practicar yoga y gimnasias orientales, librerías con temas especializados. Aparecen negocios de lo irracional: meditación trascendental, hipnosis, magnetismo, parapsicología y el control mental. La búsqueda de la espiritualidad está modificando las actividades humanas, las prioridades, el ocio y los patrones de gasto. El yoga, el taichí o la meditación son, a la vez que una manera de aliviar tensiones para el que los practica, un nuevo negocio (Aburdene, P. 2006). Esta necesidad de escapismo, a la vez que de búsqueda de fuerzas, o energías salvadoras puede estar en la base del éxito de

películas como "Crepúsculo, vampiros adolescentes" o "La Legión”. Antena 3 estrena "No soy como tú", donde se narra la historia de amor entre dos adolescentes mitad humanos mitad vampiros. "Angelology" de Danielle Trusoni (2010) se ha convertido en un bett-seller inmediato.

\subsection{Recrear un mundo imaginario - Reformular la realidad}

Una segunda estrategia consiste en construirse un mundo a la medida de nuestros deseos. Es en definitiva, la evasión de la realidad en estado puro, reformulándola para vivir una vida imaginaria. Frente a lo cotidiano y lo real podemos reinventar el mundo que nos circunda porque hay una necesidad clara de evadirse del mundo tal como lo vivimos y olvidarnos de una realidad que se percibe como decepcionante y aburrida, ¿cómo?, viviendo una vida de ficción. Como apunta lipovtesky (2008):

"Cuanto más decepcionante es la sociedad más medios implementa para reoxigenar la vida. La ilusión es también uno de los medios para salir del pesimismo".

Basta con observar en la televisión las campañas publicitarias para darnos cuenta que existen marcas con una mayor predisposición a ser consumidas en estas situación de 
necesidad de evadirse. Coca-Cola, Donuts o Nespresso activan la palanca del impulso a escaparse, del derecho a mimarse. (Cortadillas y Manillos, 2010).

Pero el gusto por la evasión puede escenificarse en nuestras vidas de distintas formas.¿Cómo convertir la realidad en ficción?. Podemos crear un mundo imaginario a base de maquillar la realidad, inyectándole una dosis de ficción. El éxito actual de la ficción en la televisión, el arte, y la novela está en que nos ayuda a transformar o a olvidar la realidad. De ahí la necesidad de contarse cosas.

En las cadenas de televisión se aprecia el gusto actual por los programas de ficción. Desde los realitys-shows basados en el principio de que la realidad es más rica que la ficción y que las situaciones cotidianas son minas para la creatividad, hasta los Instant movies donde su novedad radica en la cercanía en el tiempo de los asuntos que aborda, inspirados en la vida real. ¿Cómo explicar el éxito de series de ficción como "Gran Reserva" en la primera de televisión Española con venganzas, asesinatos, intrigas hasta llegar a "El internado" en Antena 3 donde en la última temporada la historia resulta a todas luces inverosímil?. ¿Qué ingrediente secreto tiene el programa del corazón "Sálvame" de Telecinco que no sea, exagerar, desvirtuar o inventar historias sobre personajes famosos?. El programa “Las joyas de la corona" de Tele 5 se une al grupo de nuevos programas sobre el lujo, el glamour y la vida desahogada. Se lleva enseñar por la tele lo bien que viven los demás. La Sexta tiene en antena "Mujeres ricas" donde cinco mujeres muestran al objetivo como es su día a día. Cuatro contraataca con "Casadas en Hollywood" sobre la vida de 4 españolas que se codean con la gente guapa de Los Ángeles.

El psicólogo argentino Jorge Bucay utiliza la ficción en forma de cuentos para dar respuesta a problemas reales de sus pacientes. En el mes de febrero de 2009, en El Reino Unido salió en la prensa la siguiente noticia : "Se divorcian por un "affaire" del marido con otra mujer....en Second Life". La demanda fue admitida ya que el marido incumplió su voto de fidelidad conyugal. 
La renuncia a lo íntimo, la exhibición de la vida personal, de los sentimientos y de las emociones, la ausencia de privacidad, este permanente show de la intimidad. es una constante en esta estrategia. En España, unos 13 millones de personas forman parte de alguna de estas comunidades virtuales -con Facebook, Tuenti y MySpace en cabeza-, aunque la cifra crece a un ritmo del $20 \%$. La masificación de las redes sociales ha generalizado un concepto que los expertos llaman extimidad, algo así como hacer externa la intimidad, y que tiene su origen en el auge de los reality shows y de la Web 2.0 (blogs, fotologs, redes sociales...). La fallecida Jade Goody, la ex concursante de la versión inglesa de Gran Hermano que criticó, amó, se casó y agonizó de cara al mundo, sería el ejemplo extremo de una tendencia de la que es difícil escapar.

Las fronteras tradicionales entre lo verdadero y lo falso se extienden más allá de la televisión. El mundo, en sí tiende a la interferencia. ¿Cómo demostrar que algo es real?. Los acontecimientos del $11 \mathrm{M}$ y $11 \mathrm{~S}$ mostraron que la realidad puede superar a la ficción. Unas armas químicas en nombre de las cuales se desata una guerra pero nadie las encuentra.

Este deseo de crear mundos imaginarios también lo podemos extender a otros ámbitos de nuestra vida cotidiana. El éxito de velas, flores, cojines, inciensos, la música ambiental...etc, demuestra este deseo de transformar el entorno vital. Es importante vestir la casa, darle un alma e inventarle una historia. La estetización de la casa y de sus objetos, incluyendo los más habituales, se convierte en una preocupación creciente. Los utensilios de cocina, son un ejemplo de esta preocupación por el diseño, en ellos la utilidad es secundaria, lo esencial radica en el aspecto. En este sentido se aprecia en el mundo de los objetos, como el diseño, buscando placer visual resulta un beneficio importante en la decisión de compra. También el mundo de la alimentación sucumbe ante este cambio, donde la belleza reviste la forma de exquisitez. Hace unos años la fantasía gastronómica en España eran: las angulas, el jamón y los percebes. Ahora han sido sustituidos por el caviar, foi-gras y champagne francés. 
Otra manera de introducir la ficción en nuestras vidas pude consistir en experimentar la trasgresión de los límites e iniciar la búsqueda de nuevas formas de libertad, comenzando por transformar la propia identidad. Las personas tienen ganas de inventarse personajes, se puede constatar en la multiplicidad de seudónimos que utilizamos para los SMS o correo, en el contenido de nuestros perfiles de Tuenti o de facebook.

Christian Salmon (2010) habla de la normalización de la trasgresión. Una característica de muchas personas del siglo XXI es que están condenadas a cambiar, a reinventarse cada día con capacidad para sorprender con diferentes apariencias. En palabras del autor "Ya no es la hora de las lolitas, sino de las mutantes". Somos estrategas de nosotros mismos y la trasgresión se está convirtiendo en norma social. La semana primera de julio de 2010, entre los libros más vendidos a nivel nacional se encuentra en el $8^{\circ}$ lugar “Reinventarse, tu segunda oportunidad" de Mario Alonso.

El campo de la publicidad es fructífero en ejemplos que escenifican esta vía de escape. En el último anuncio del Honda Civic el slogan reza así: "Revela tu otro yo". Por otro lado en el actual anuncio del desodorante AXE se nos muestra un hombre mutante en función de las circunstancias que se le presentan. Su slogan es: “La mujeres se aburren fácilmente. Nuevo AXE Twist. La fragancia que cambia durante el día".

Este buscar nueva formas de identidad se puede traducir en jugar con el cuerpo. El cuerpo y la imagen son el reflejo de lo que llevamos dentro y cada vez se percibe más como una materia prima que se puede moldear. No existen límites para forjarse un cuerpo más cómodo, más joven, cada vez más excepcional. La diversidad de opciones que nos presenta la cirugía estética se amplia sin parar. El cuerpo (Ergo 1999), se ha transformado en objeto de deseo y admira su propia belleza. Estamos ante un nuevo fenómeno de marcado cariz narcisista. El placer de seducir, de ser admirado, solicitado, atractivo. 
Una consecuencia de este narcisismo es el culto a la eterna juventud. La vejez está devaluada. Amando de Miguel (1990) dice en su libro "Así somos los españoles", refiriéndose al culto al cuerpo: "se mima el cuerpo no porque se tenga miedo a la muerte o al más allá, sino porque se tiene miedo a dejar el más acá".

Como apunta M.S. Martin Requeno (2007), este movimiento a favor del culto al cuerpo mueve cifras millonarias, se puede afirmar que la industria cosmética está en plena ebullición, según un informe del sector en 2004, hubo un movimiento de cerca de 7.000 millones de euros ( un 6,5\% más que el año anterior, según la Asociación Nacional de Perfumería y Cosmética). Esta excesiva preocupación provoca la sensación de su propia debilidad y se sensibilizan las posturas con comportamientos patológicos. De ahí los grandes temores a cualquier plaga de tipo social (droga, cáncer, SIDA, la gripe A).

En prensa, radio y televisión se exalta un modelo estético en el que se valora el cuerpo, delgado, moreno, joven...etc. Es necesario aparentar dinamismo, belleza, deportividad, ser sexy y atractivo. Los anuncios publicitarios nos ofrecen y prometen: Dietas de adelgazamiento en poco tiempo y sin esfuerzo ("Adelgazante Manasul: Pierda 10 kilos en 30 días"), productos eficaces para ensombrecer el envejecimiento (“Just for men y adiós a las canas"). El hombre se ha acercado al mundo tradicionalmente femenino de la cosmética, alejándose del arquetipo de hombre duro y viril que rechaza los cuidados corporales.

El empeño por modelar el cuerpo remite al ideal de eterna juventud y no cabe duda de que la infancia y la juventud son dos importantes fuentes de inspiración para combatir las frustraciones adultas porque madurar es envejecer. De ahí el afán por vivir en una adolescencia infinita. El adolescente está en vías de convertirse en adulto, todavía no lo es. Es por ello que se le permite todo, nada esta impuesto ni es definitivo, al contrario que el adulto. 
En las sociedades históricas el hombre que se imponía era el adulto. Pero, con el paso del tiempo, lo esencial no es ya la experiencia acumulada, sino la adherencia a la vitalidad. Así, por ejemplo, la sensatez de los viejos se convierte en chochez. Poco a poco se tiende a rejuvenecer la figura del hombre. La juventud va subiendo en edad, así en los años 30 las estrellas femeninas apenas pasaban de los 25 años. Ahora nos encontramos con actrices que superan ampliamente los 40. La vejez está devaluada y la juventud se convierte en adolescencia. Sharon Stone a sus 50 años realiza un spot de un crema de belleza en la que se ensalza la juventud.

Mucha de la publicidad actual tiene el objetivo de crear un sentimiento de urgencia sobre la necesidad de conservar la juventud y fomentar el temor al envejecimiento. Así, los jóvenes son imitados desde su estética, sus cánones de belleza, su apego a la moda, su despreocupación y su defensa de ser un "énfant terrible" de por vida. Los adultos juegan a ser Peter Pan, intentan mantenerse en la eterna juventud, vivir con cierta despreocupación, disfrutar libremente, en muchos casos imitando a los hijos.

A un nivel aspiracional, la sociedad actual se construye idealmente imitando El país de nuncajamás (Gónzalez, A. y Muñoz, N. 2001). Hace no muchos años, las hijas adolescentes imitaban en su estilo, vestuario, a sus madres, ahora son las madres las que vuelven la mirada al look de sus hijas.

En la asimilación de una nueva juventud los consumidores juegan a la consola o la Wi. Inicialmente pensadas para niños y adolescentes, los adultos y adultas de más de 30 años juegan durante largas horas . ¿Quién tiene un Ipod ?¿Un joven?, no, el que quiere. Javier Rovira (2010) apunta como el promedio de edad de la persona que compra los videojuegos en España es de 38 años. Personas de más de 50 años suponen el 24\% del grupo. Resulta también curioso el hecho de que el 40\% de los consumidores de CocaCola tienen más de 35 años. 


\subsection{El cambio a un nuevo modelo}

Las estrategias anteriores suponen posturas egocéntricas, centradas en uno mismo. No transforman la realidad, al contrario se mantienen pasivas ante ella. Como contrapunto surge el hombre que se entrega a la misión de transformar la actual sociedad.

Cambiar consiste en cuestionar el presente, rechazarlo y generar nuevas oportunidades para vivir de otro modo. Esta estrategia sugiere que el individuo puede ser el dueño de su destino. Los actos de violencia de Francia en Octubre de 2005 o los movimientos antiglobalización, son algunos ejemplos.

Son varios los comportamientos que podemos observar en relación a este movimiento. Uno de ellos es el compromiso. No se trata de una acción ideológicamente contestada, sino la expresión de un hastío global frente al mundo consumista. Cada vez son más las grandes empresas que colaboran en el impulso del comercio justo, para mejorar el acceso al mercado internacional de los productores más desfavorecidos, sobre todo de países en vías de desarrollo. Carrefour, Eroski, El Corte Inglés y otros distribuidores venden productos de comercio justo. También la banca ha encontrado en esta estrategia un nuevo nicho de mercado, cabe mencionar "Los planes de pensiones solidarios Bancaja".

En el ámbito social y político es fácil comprobar el aumento de la capacidad crítica de los individuos. Se producen manifestaciones a través de plataformas como las que tuvieron lugar durante la catástrofe del Prestige, las distintas asociaciones de víctimas del terrorismo, o las acciones de las asociaciones de consumidores que con su crítica a la publicidad han conseguido la retirada de spots publicitarios. El creciente escepticismo del consumidor frente a la publicidad ha dado un giro a las estrategias de los anunciantes que están apostando por modelos normales y cercanos. Dove, la marca de higiene personal de Unilever, se sirve en sus campañas de modelos que superan la talla 38. En la política podemos recordar la concentración anta la calle Génova, sede del Partido Popular, justo antes de las lecciones nacionales de 2003. 
Las ganas de parodiar y burlarse refleja ese mismo fenómeno. El regreso al cine de parodias con Torrente. En televisión espacios como La escobilla nacional, personajes como Chiquilicuatre.

En una sociedad determinista, se pretende reintroducir por medio de la crítica el sin sentido. Así urgen los Flash Mob, o muchedumbres instantáneamente que gracias a las nuevas tecnología invitan a la movilización, bien para realizar un acto público, o bien para pasar un rato agradable. No están construidas en torno a la convicción sino a la emoción. Surgieron en el verano de 2003 en New York y se extendieron a gran velocidad por todo el mundo. En la ciudad de los rascacielos más de 200 personas se quedaron congeladas en la estación central. En Japón 120 individuos se convirtieron en gallinas durante dos minutos. Pasado ese tiempo cada uno dejó un huevo en su lugar y se marchó como si nada.

En España, una de las primeras Flash Mobs de las que se tiene constancia tuvo lugar en Barcelona en octubre de 2003.

Pero no se trata sólo de rechazar, sino también de proponer alternativas, de buscar soluciones a los problemas de la humanidad. Así frente a una sociedad mercantilista, donde todo se compra y vende, la gratuidad quiere ser el contrapunto del "todo por la pasta". En www.sindinero.org, los internautas dejan regalos para aquellos que los quieran

El Book Crossing es un ejemplo de esta gratuidad crítica: "Si te ha gustado un libro, deja que fluya". Este es su principio, que consiste en "abandonar" libros, en estaciones de metro, cafeterías, universidades, museos, para que otros los encuentren, los lean y los liberen de nuevo . Se trata de un movimiento global surgido en 2001 por iniciativa del estadounidense Ron Hornbaker que defiende que los libros están hechos para caminar, tal y como reza el lema del bookcrossing. 
En una campaña reciente de Tele 5, Mercedes Milá animaba a compartir los libros. Lo más interesante de este movimiento es que es posible saber cual ha sido el recorrido del libro ya que se registran en una base de datos de bookcrossing en Internet. Cuando nos encontramos con uno lleva unas etiquetas que lo identifican y que nos ayudan a través de una consulta en la red a conocer las experiencias de anteriores lectores que comparten sus comentarios (www.bookcrossing-pain.com).

En otro orden de cosas es creciente el número de turistas que a través de internet intercambian sus hogares por unos días, semanas. (www.intercambiocasas.com), hasta llegar a lo último para viajar, se llama cochsurfing y es una red social con millón y medio de socios que ofrecen gratis un rincón de su casa.

Otra alternativa tiene que ver con el valor del tiempo. Al vivir en una especie de estado de urgencia el individuo dispone de poco tiempo para él. Como reacción surgen distintas propuestas. En Estados Unidos surgió el movimiento “Downshifting”. Una tendencia adoptada por los yuppies de los años 80 y que sigue calando en todo el mundo. Sus principios: trabajar menos y vivir más, renunciar a sueldos muy altos a favor de una vida de calidad. Tomarse su tiempo, darse un respiro, dejar de considerar el trabajo y la urgencia como las únicas modalidades de la vida humana.

Vivir más despacio es posible. Así nació la red CittaSlow, que agrupa a ciudades de ritmo relajado, sostenibles en todo el mundo. Se trata de ciudades con menos de 50.000 habitantes, que en sus mercados hay productos ecológicos, tienen zonas peatonales, edificios sostenibles y restaurantes de delicias locales. En España pertenecen a este club localidades como Begur, Bigastro, Lekeitio, Munguia, Palafrugel, Pals o Rubielos de Mora. Este movimiento nació en Italia en 18986 cuando un grupo de ciudadanos con el crítico gastronómico Carlo Petrini a la cabeza se rebelaron cuando cerró una de las tiendas más tradicionales de la Plaza de España en Roma y la convirtieron un restaurante Fast Food. De ahí surgió la plataforma "Show food" cuya filosofía se ha 
extendido a distintos ámbitos. Apuestan por el ritmo lento y consciente en la cocina, la escuela...etc.

Por último, podemos mencionar el "Banco del tiempo" en intertiempo@yahoo.com o el Laboratorio de economía solidaria.

Por último, otra alternativa es la búsqueda de la simplicidad. Según Carat (2005) un estudio europeo realizado por Datamonitor, demuestra que 41 millones de europeos se plantean cambiar sus marcas tradicionales por marcas reorientadas hacía el beneficio de la simplicidad.

Fiel a esta política es René Redzepi, chef que dirige el restaurante Noma en Copenhague y que acaba de ser coronado en abril como el mejor cocinero del mundo. Si algo le distingue es el empleo de productos naturales en sus platos. Como el mismo dice: "Hago una cocina ecológica, verde auténtica, sin muchos lujos". Renuncia a la cocina francesa. No usa ni foi-gras, ni nata, ni aceite. Tampoco pone manteles en las mesas.

Sustain Dane (www.sustaindane.org) es una organización sin ánimo de lucro que ofrece, entre otros, cursos dedicados a simplificar nuestras vidas. Algunos de los temas propuestos en estos cursos son: "Vivir más con menos", "Tu dinero o tu vida", “¿Cuánto es bastante?”.

Para finalizar una pregunta se hace necesaria, el dinero y la riqueza ¿dan la felicidad?. En Marzo de 2008 Marcos de Quinto, presidente de Coca-Cola España presentó el primer informe Coca-Cola de la felicidad. Según dicho informe dos de las claves están en nuestra conexión con la gente (las relaciones personales) y la generosidad (la disposición a donar, a participar en asociaciones humanitarias).

La felicidad se ha convertido en una obligación, incluso en objeto de consumo. Sin embargo, aunque comprar puede ser un acto muy placentero lo cierto es que no nos hace felices. 


\section{REFLEXIÓN FINAL}

Esta crisis está provocando cambios profundos de manera que las reglas del juego han cambiado. Debemos ser conscientes de que nos enfrentamos a un consumidor nuevo y en plena evolución. La aversión al riesgo ha llegado para quedarse y el temor inhibirá durante mucho tiempo la asunción de riesgos a largo plazo. Las personas necesitan reestructurar de nuevo su sistema de valores, vivir orientadas, con estabilidad y un margen de certidumbre, de ahí que se acomode y cambie para ajustarse mejor al nuevo contexto.

La consecuencia final es una agudización de los comportamientos descritos dominados por la incertidumbre hacia el futuro. Se percibe, por tanto, un abismo entre el pasado y el futuro incierto. Difícilmente todo vuelva a ser como era antes.

\section{BIBLIOGRAFÍA}

- ABURDENE, P. : "Megatendencias 2010. El surgimiento del capitalismo consciente". Barcelona. 2006. Granica.

- BAUMAN, ZYGMUNT: "Modernidad líquida". Argentina.2005. Fondo de Cultura Económica.

- CASTEL, R.: ¿Quées estar protegido?. Buenos Aires. 2004. Editorial Manantial.

- CORTADILlAS, D. Y MALILlOS, A.: “¿Qué hay que hacer para salir de la crisis?".Barcelona. 2010. Revista Investigación y Marketing No 106. Pp.38-40.

- DE MigUel, A.: "Los Españoles. Sociología de la vida cotidiana". Madrid. 1990. Temas de Hoy. 
- ERGO. : "De la sociedad al individuo. Evolución del sistema de valores de la España de finales del siglo XX.".Pág. 74. Madrid. 1999. Editado por ERGO ADVANCED RESERACH, S.A. Madrid

- GARRIDO, R.: "Diferentes reacciones ante la crisis". Barcelona. 2006. Revista Investigación y Marketing. No 102. Pp. 6-10.

- LIPOVESKY, P.:"La sociedad de la decepción". Barcelona. 2008. Anagrama. Colección argumentos.

- MARTIN REQUENO, Ma. I: "Creatividad publicitaria y nuevas tendencias de consumo". En M. I. Martin Requeno y M. C. Alvarado López (Coordinadoras). 2007. Nuevas tendencias en la publicidad del siglo XXI. Ediciones y publicaciones: Comunicación social n 5 .

- ROVIRA, J.: “Consumering”. Madrid. 2009. ESIC.

- SALMON, C.: Kate Moss machina". Barcelona. 2010. Peninsula.

- THE COCKTAIL ANALYSYS: "Informe de resultados Observatorio Redes Sociales. $2^{a}$ oleada". 2010. En http://tcanalysis.com/uploads/2010/02/tca-

- ZULOAGA, A. Coordinador : "Las tendencias sociales y su impacto sobre los medios de comunicación y la publicidad.". Barcelona. 2005. Carat Expert..División de Investigación.

- Informe Coca-Cola sobre la felicidad (2008): www.institutodelafelicidad.com 